\section{Mesotelioma a una edad inesperada}

\author{
Mesothelioma case occurring at an unexpected age
}

Presentamos el caso de un varón de 38 años, deportista, sin hábitos tóxicos ni antecedentes médicos de interés que trabajó como supervisor en un área de soldadura de una empresa naval durante cuatro años (en el momento actual no trabaja) con escaso contacto con tóxicos inhalados. El año previo había presentado una inhalación accidental de galvanizado de zinc. Acude al servicio de urgencias por cuadro de un mes de evolución de dolor torácico localizado en hemitórax derecho. Se realiza una radiografía de tórax en la que se observa un pinzamiento del seno costofrénico derecho y engrosamiento de la cisura menor en relación con derrame pleural y lesiones lineales en base derecha y en el lóbulo medio (Figura 1). Se solicita una TAC de tórax de forma basal (paciente con alergia al contraste yodado) que muestra un engrosamiento nodular de la pleura derecha con afectación de la pleura mediastínica (Figuras 2 y 3). Para completar el estudio de la lesión se realiza una biopsia pleural quirúrgica por videotoracoscopia confirmándose el diagnóstico de mesotelioma maligno bien diferenciado de tipo epiteloide. Ante este diagnóstico se le practica al paciente una neumonectomía extrapleural derecha (resección del pulmón, pleura parietal, adenopatías mediastínicas, pericardio y diafragma ipsilateral colocando una prótesis de politetrafluoroetileno expandido en la zona del diafragma para evitar la herniación abdominal) y tratamiento adyuvante con quimioterapia y radioterapia torácica ipsilateral (radioterapia de intensidad modulada de dosis).

El mestelioma es un tumor derivado de las células mesoteliales. El 80\% de los casos tiene su origen en la pleura. Es relativamente infrecuente; su incidencia en países de la Unión Europea es aproximandamente de 1,5 casos por 100.000 habitantes cada 5 años, con un pico de presentación en personas entre 50 y 70 años. La causa fundamental del mesotelioma pleural es la exposición al asbesto y se están estudiando algunas alteraciones genéticas que podrían predisponer al desarrollo de la enfermedad. La manifestación clínica más frecuente es el dolor torácico y el diagnóstico de certeza requiere confirmación anatomopatológica. El tratamiento de elección es la cirugía con quimioterapia y/o radioterapia torácica ipsilateral adyuvantes. Es conocido que la inhalación de galvanizado de zinc produce patología pulmonar aguda, pero tras una revisión exhaustiva no hemos encontrado asociación con el mesotelioma. Respecto a su trabajo como soldador, profesión relacionada con el mesotelioma, el paciente trabajó como supervisor de área de soldadura con escaso contacto con tóxicos inhalados, el tiempo de exposición no fue prolongado y el periodo de latencia entre la exposición y la enfermedad fue demasiado corto. En la anamnesis dirigida el paciente relató que durante su infancia acompañaba a su padre a su trabajo frecuentemente (manipulaba uralita para aislamiento de tuberías que está descrita como exposición ocupacional por la Orden Ministerial de 31 de Octubre de 1984 y exposición doméstica al quedar fibras de asbesto en la ropa de trabajo). Esta exposición encajaría con el período de latencia de 30 años entre exposición al asbesto y la presentación de la enfermedad que existe en los casos típicos de mesotelioma. Consideramos que este puede ser el factor etiológico principal, aunque no descartamos la posible influencia de su trabajo como supervisor de área de soldadura.

\section{Bibliografía}

1. Isidro Montes I, Abu Shams K, Alday E, Carretero Sastre JL, Ferrer Sancho J, Freixa Blanxart A, et al. Normativa sobre el asbesto y sus enfermedades pleuropulmonares. Arch bronconeumol 2005; 41: 153-68.

2. Kazan-Allen L. Asbestos and mesothelioma: worldwide trends. Lung cancer. 2005; 49 Suppl1: S3-8

\section{Diagnóstico: Mesotelioma a una edad inesperada Judith Álvarez Otero ${ }^{1}$, Ana Cobas Paz ${ }^{2}$ \\ ${ }^{1}$ Servicio de Medicina Interna, ${ }^{2}$ Servicio de Neumología. Hospital Povisa. Vigo}

Figura 1. Rx tórax AP. Se observa un pinzamiento del seno costofrénico derecho y engrosamiento de la cisura menor en relación con derrame pleural y lesiones lineales en base derecha y en el lóbulo medio

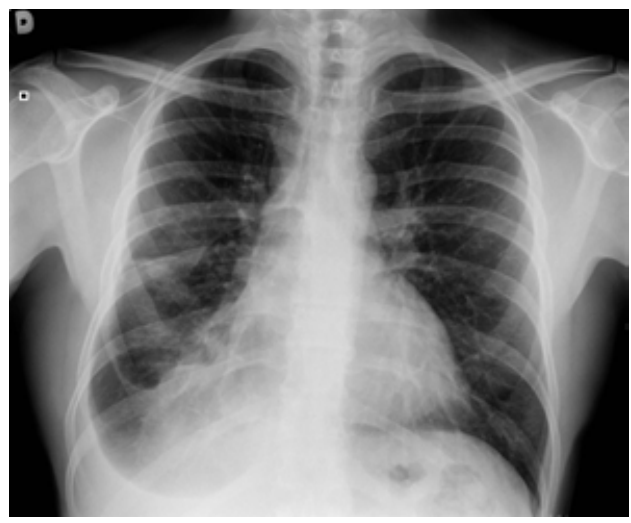

Figura 2. TAC axial. Engrosamiento nodular de las cisuras mayor y menor y de la pleura derecha con afectación de la pleura mediastínica que condiciona pérdida de volumen.

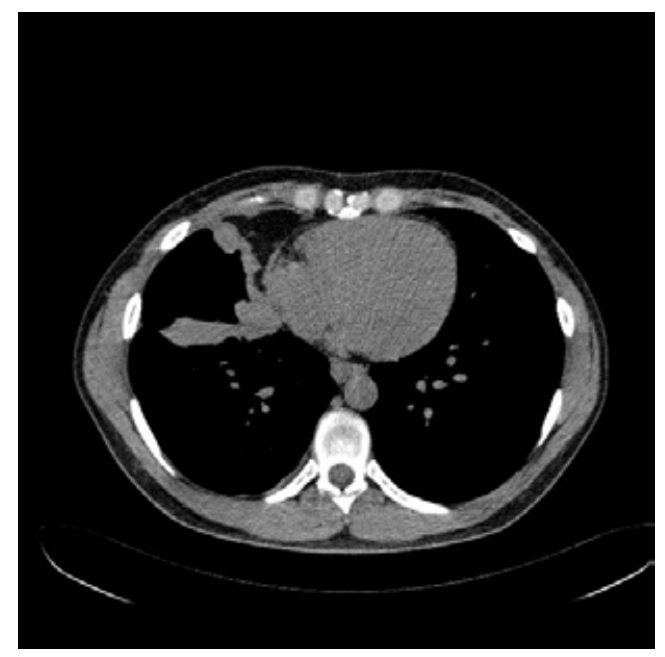

Figura 3. TAC coronal. Engrosamiento nodular de las cisuras mayor y menor y de la pleura derecha con afectación de la pleura mediastínica que condiciona pérdida de volumen.

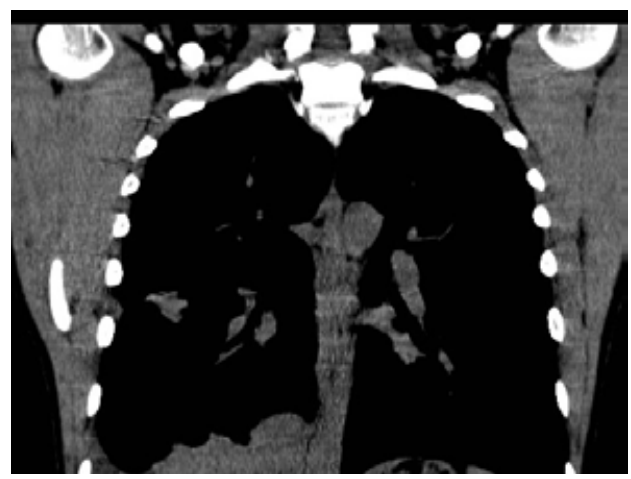

Correspondencia: judithao@hotmail.com

Como citar este artículo: Álvarez Otero J, Cobas Paz A Mesotelioma a una edad inesperada. Galicia Clin 2014; 75 (1): 43 Recibido: 7/8/2013; Aceptado: 29/11/2013 